\title{
Temporary spatial transformations in residential area corridors due to the impact of tourism. Case study: Jalan Jaksa, Jakarta
}

\author{
V. Haristianti \\ Telkom University, Bandung, Indonesia \\ W.D. Pratiwi \\ Institut Teknologi Bandung, Bandung, Indonesia
}

\begin{abstract}
This study aims to determine the extent to which the impact of the event affects the creation of a temporary territorial transformation of the corridor structure. This research is qualitative research. The research variables are changes in soft space found in residential corridors, including the width of the road area on the sidewalk, and the garden of the residence. Sampling was carried out by means of before and after studies which emphasized the observation of literature study results and direct observation. The results showed that the significance of sidewalk changes can be seen during the day and at night where there is a change in function, as well as the crowd. Changes in the function of the sidewalk area and road buildings when there are activities are not merely spatial changes, but also affect the territorial structure, namely the occurrence of changes in depth sequences in the spatial strata.
\end{abstract}

Keywords: temporary spatial transformation, tourism area, digital mapping, depth sequence changing

\section{INTRODUCTION}

Tourism as an integral part of global business is highly dependent on seasonality, economic activities and human behavior and society in general (Corluka 2019). In its implementation, the built environment as a place to carry out an activity has a very close relationship with tourism. Habraken (1998) likens the built environment as an organism. He said that every change that occurs is a representation of the values adopted from the time of the ancestors to the future generations and changes in the built environment itself based on changes in the cultural value system adopted by the community (agent) who has power (controls). The result of the movement of people carrying out activities in the built environment at one time is called an event. The nature of the space used by humans to carry out events can be permanent or temporary. In permanent space, the function of space will remain the same under any circumstances. Whereas in temporary space, the function of the space will be different at a certain time.

The process of transformation contains the dimensions of time and the socio-cultural changes of the people who occupy a place, emerge through a long process and are always related to activities that occur at that time. (Alexander 1987, Pakilaran 2006 in Pratiwi 2009). In the process of transformation, there is a term called territory which means space under regulation or supervision (Habraken 1998). Territorial depth can be measured by the number of crossings required to move from the outermost region to the deepest region. This is shown in the Depth Sequence Diagram, namely the principle relationship for entering the transition between private and public spaces which is described in different ways to be able to access territorial areas (Susanti et al. 2018).

This paper is intended to highlight the relationship between the built environment and tourism. Specifically, it will discuss how spatial transformation occurs in temporary spaces in the corridor 
of a settlement area due to events. The residential area that will be the object of study is Jalan Jaksa, Central Jakarta. This road is known to have a long history. The development of a residential area into a tourism area has occurred since the end of 1968 until now. Since 2011, Jalan Jaksa has been designated as a Night Tourism Area. The contents of the DKI Jakarta Provincial Governor Regulation Number 53 of 2011 concerning Guidelines for City Design for Special Areas of the Jaksa Street Corridor states that the emphasis on the arrangement of the Jalan Jaksa corridor is on the arrangement of mass of buildings, facades, pedestrian tourist routes and public space planning. In more detail, Jalan Jaksa is projected to be built into a central corridor for tourist accommodation, entertainment and snacks that are attractive and nuanced to local Jakarta culture and are active for 24 hours, but still comfortable to live in and friendly to pedestrians. Jalan Jaksa is expected to become a special corridor for left-to-time traffic through traffic restrictions and setting maximum parking standards.

The ebb and flow of objects and tourist attractions in Jalan Jaksa is greatly influenced by the Indonesian economic situation (Haristianti \& Pratiwi 2020). The changes that occurred on Jalan Jaksa were very dynamic. In this case, the transformation process occurs due to supply-demand in the form of visitor needs, as well as tourists and the response of local communities. Therefore, the discussion regarding temporary spatial changes in the corridor of Jalan Jaksa is considered worthy of discussion because it has many relationships with other aspects of society, including economic and social aspects. The purpose of this paper is to determine the extent to which the impact of the event which causes temporary spaces in the corridor to appear at certain times has an effect on the creation of territorial transformation in the corridor structure. The research, which was carried out as an academic exercise, is expected to produce new knowledge related to spatial transformation of the Corridor on Jalan Jaksa. The collected information is also expected to be a recommendation for related parties (for example local governments) to monitor the course of changes that have occurred in this area so that it becomes more focused and sustainable.

\section{RESEARCH METHOD}

The research method used in this paper is a qualitative method (Creswell 2002) with a time setting of before and after studies (also known as the pretest / post-test design (Kumar 2005) with a number of contacts twice. The sample is carried out by comparisons of two time periods, namely past conditions from Google Earth Satellite digital data, as well as direct observations. The aim is to obtain a clear picture of the changing situation in the corridor of the case study area to assess the direction of its temporary spatial transformation. Soft space attribute that can be used as a benchmark for assessing spatial transformation, including the width of the road area on the sidewalk, public open space for residents, the garden of the occupancy and road attributes.

\subsection{Data collection method}

The primary data collection method uses field observation methods compared with the results of documentation in the form of past photos obtained from satellite photos and also digital documentation from various sources. At this stage, the writer acts as a non-participant (Kumar 2005). In the first observation, the authors compared the results of satellite photos from $2004-2014$ and examined the spatial parts of the residential corridors that are likely to change when viewed from satellite capture by means of montage. After that, the results of these observations are used as a reference for conducting direct surveys. As for the second survey stage (direct survey), the sample was selected by non-random or probability sampling by selecting the parts of the corridor that were seen to have changed from the data obtained in the first survey. To enrich the information, the authors also conducted unstructured interviews with business owners and visitors who were in the case study location in the sampling area. 


\subsection{Data analysis method}

Data analysis was carried out in a qualitative way (Creswell 2002). After the field observation process is complete, the results of the literature and field documentation are directly compared and analyzed by means of data coding and text data analysis (Kumar 2005) for further descriptive interpretations based on predetermined variables. To enrich the results of the analysis, the authors also collect secondary data in the form of theory and earlier research as well as the results of personal documentation from residents of Jalan Jaksa as well as documents from internet reviews related to special events (for example: Jalan Jaksa festival, Republic of Indonesia anniversary) which occurs at the case study location and is considered the peak season time to enrich the description of the interpretation results.

\section{RESULT AND DISCUSSION}

\subsection{Result}

The results of satellite mapping observations in the years 2004-2014 show that there are many points that have undergone spatial changes. The results of these changes can be seen in the image below:

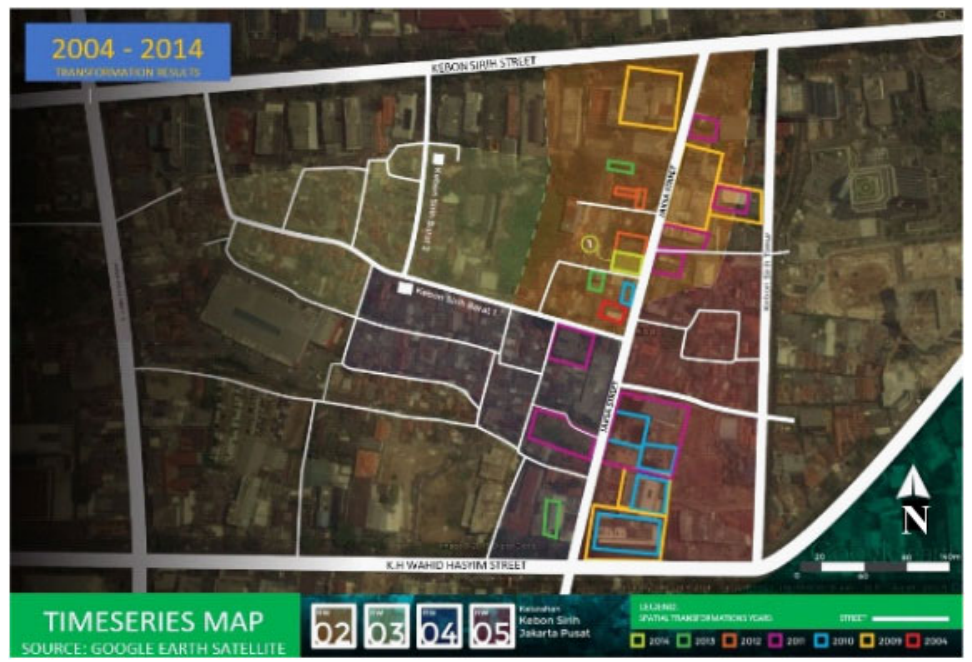

Figure 1. Map of distribution of spatial change in settlements on Jalan Jaksa. (source: author documentation)

The mapping of the satellite photo observation results above is then used as a reference when making direct observations. The results of direct observations show that, apart from the main zone (zone 1) there are also several other zones that have changed. From the results of direct observations, it is found that the changes that occur in roads and corridors (sidewalks) cannot be separated from the role of street vendors (PKL) who are on Jalan Jaksa and its surroundings. After doing the mapping, the results show that the street vendors already have a place / zoning that is devoted to their trading. Then, the PKL category was divided into three sample zones. The sampling itself was carried out at three different PKL special points in zone 1, 2 and zone 3.

From the distribution map below (Figure 2), three different zones of corridors and public spaces are usually used by street vendors for selling. Interestingly, from the observations it was found that the thing that distinguishes zones 1, 2 and 3 is the time to sell street vendors. For street vendors selling in zones 1 and 2, their presence is at night. During the day, this area is not used for selling and functions only as a sidewalk as well as an ordinary road shoulder. However, in the evening 


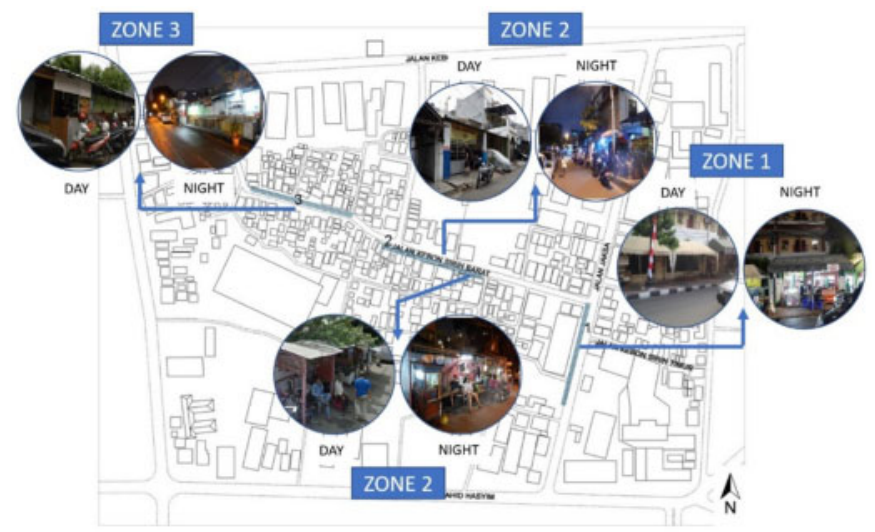

Figure 2. Map of the distribution of case study sampling. (source: author documentation)

before sunset, this area will begin to be crowded with sellers who make preparations to sell at night until it approaches midnight. Zone 1 and zone 2, will be crowded at night. Zone 1 is more crowded with migrants from outside Jalan Jaksa, while zone 2 will be crowded with local residents because near area 2 there is a gazebo which residents use as a shared outdoor space. Whereas in zone 3, crowds occur during the day. Street vendors in this area trade from morning to evening and this area will be quieter at night.

The purpose of street vendors selling every day in this area is as a place for office employees located around Jalan Kebon Sirih to eat during lunchtime breaks. In addition to changes in function and the busyness of the sidewalk area during the daytime and at night, the sidewalks also often undergo renovations and also changes from street vendors where at some point, street vendors change their building structure from temporal to more permanent. sidewalks change frequently. These changes include in terms of maintenance (excavation, material replacement) carried out by the government. In addition, it can also be seen how some street vendors often change their selling areas to become more permanent on occupied sidewalks. In zone 2, some also show that the sidewalks in the corridor of Jalan Jaksa and its surroundings undergo a temporal spatial transformation due to changes in usage during the day and at night. In addition to the changes in the sidewalk, there are other public space points which are also allegedly changing frequently in this area, including the karang taruna gazebo and the gazebo where residents gather also the sidewalks

\subsection{Discussion}

The change in the function of sidewalks and road shoulders when there is an activity compared to the absence of this activity is not merely a spatial change, but also affects the territorial structure of the open space. The existence of activities allows space to form new territories where the levels can be seen in the illustration image below which is adapted from the theory of Habraken, 1998 regarding depth sequence diagrams:

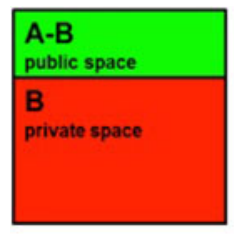

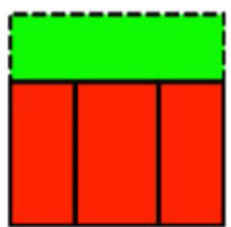

$\mathbf{A}$

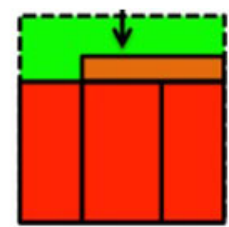

B

Figure 3. Illustration of the rise of the sidewalk territorial structure to become more private during the activity. 
When viewed from the perspective of the existence and function of sidewalks and road shoulders, the increased activity of residents leads to an increase in the territorial structure of the sidewalks and road shoulders where the initial function determines that the area is a free area (public space) but when the activity occurs, the area experiences layers of imaginary levels. Where some of the areas are semi-public areas, namely areas where street vendors, or residents sit, indicating that pedestrians cannot enter the area as freely as they can if there are no street vendors or residents doing activities. Meanwhile, when viewed from the point of view of B to A (private area to public area), this situation causes a decrease in the level of territory or level as described in the illustration below:

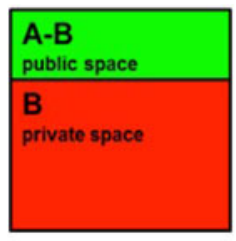

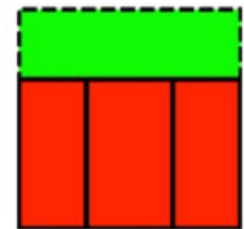

$\mathbf{A}$

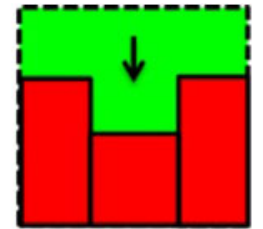

B

Figure 4. The illustration of the decline in the territorial structure becomes more public on the residents' yard when there is activity on the sidewalk.

From the illustration above, it can be explained that when viewed from private (B) to public (A-B), the time when the activity takes place is the time when the territorial structure decreases. This can be proven by changing the use of private facilities such as the main gate and garage, where when there is no activity it is the private area of the owner of the residence, while when there is an activity it turns into a public area that can be used by residents as a place to wait for food, a place to chat, etc. So it can be concluded that the spatial transformation of the corridor can cause changes in the territorial strata of the public space.

\section{CONCLUSION}

The existence of digital media is very helpful in the process of mapping the direction of the corridor's spatial transformation that occurs. The spatial transformation of the corridor on Jalan Jaksa and its surroundings can cause changes in the territorial strata of the public space. The direction of the changes that have occurred has not yet fully led to the Regulation of the Governor of DKI Jakarta Province Number 53 Year 2011 concerning Guidelines for City Design for Special Areas of Jalan Jaksa Corridors. Currently, the condition of Jalan Jaksa corridor continues to decline. For this reason, the role of the government is needed especially to monitor the direction of transformation and improve the quality of events that are on the agenda of the Jaksa Street corridor, including the Jaksa Street Festival and the Celebration of Indonesian Independence. This research was conducted based on the experiences obtained from the findings, and observations of researchers when conducting field studies in research locations (empirical). It is possible for further research to develop this topic towards phenomenological research.

\section{REFERENCES}

Corluka, G, 2019. Tourism seasonality-an overview.

Creswell, J. W,2002. Research design: qualitative, quantitative, and mixed methods approaches. Second edition, Sage Publications, International Education and Professional Pubisher.

DKI Jakarta Provincial Governor Regulation No. 53 of 2011 concerning City Design Guidelines for the Special District Corridor for the District Attorney. 
Habraken, N.J, 1998. The structure of the ordinary: form and control in the built environment. The MIT Press, Massachusetts.

Haristianti, V. and Pratiwi, W.D, 2020. Transformasi spasial hunian pada eks-backpacker enclaves studi kasus: jalan jaksa, jakarta pusat. RUAS (Review of Urbanism and Architectural Studies), 18(1), pp.52-63.

Kumar, R, 2005. Research methodology: a step by step guide for beginner. London, Sage Publication.

Pratiwi, W.D, 2009. Tourism in traditional Bali settlement: Institutional Analysis of Built Environment Planning, Verlag Dr Muller.

Susanti, I.S., Dewi, N.I.K. and Permana, A.Y., 2018. Tatanan teritorial dalam proses transformasi hunian. Jurnal Arsitektur ZONASI, 1(1), pp.27-37. 